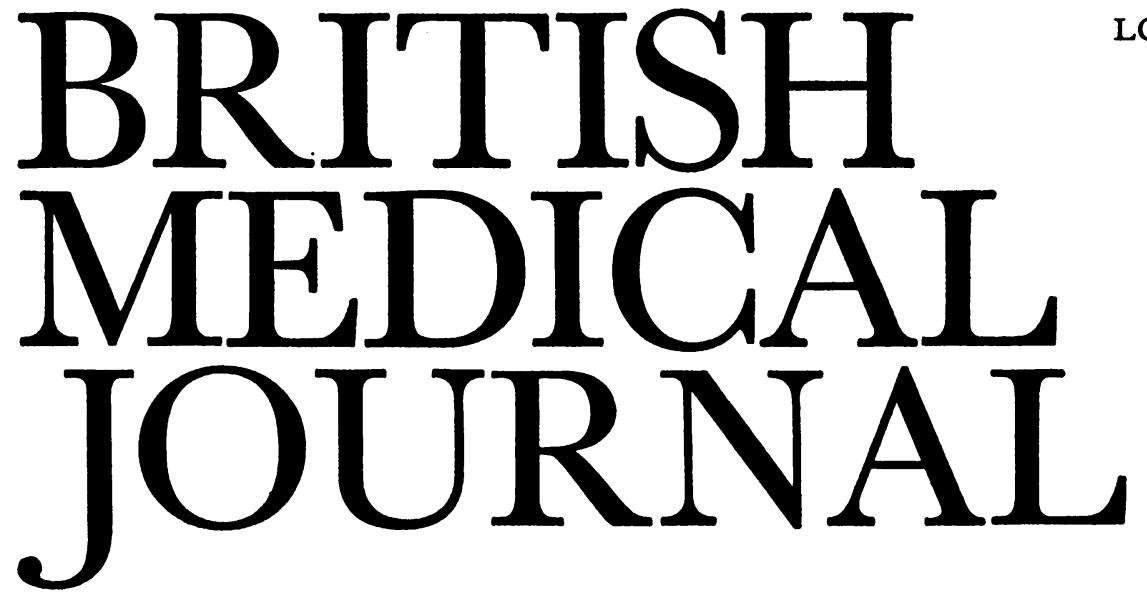

LONDON SATURDAY 23 SEPTEMBER 1972

\title{
Immunosuppression and Malignancy
}

The increasing use over the past decade of powerful immunosuppressive drugs provides an opportunity for testing the validity of the theory that cancer results from a breakdown of the body's "immunological surveillance." This concept, first proposed by L. Thomas ${ }^{1}$ and since developed by Sir Macfarlane Burnet, ${ }^{2}$ holds that such a breakdown allows the proliferation of abnormal cells, with the eventual result of overt malignancy.

Some four years ago reports from widely separated centres in Scotland, New Zealand, and the U.S.A. of reticulum cell sarcomas in patients on immunosuppresive therapy after renal transplantation brought the issues to attention. The occurrence of several cases of so rare a disease in only a few recipients of transplants could not easily be attributed to chance. Largely owing to the efforts of I. Penn and his colleagues at Denver, Colorado, who have kept an informal registry of malignant neoplasms in the recipients of organ transplants, other similar cases have been documented. So far at least 17 reticulum cell sarcomas and two unclassified lymphomas have been reported in approximately 5,000 recipients of transplants and of immunosuppressive treatment. ${ }^{3-5}$

Full details of one case of reticulum cell sarcoma involving the meninges have not yet been published, 5 but of the remaining 18 cases 13 occurred in males and 5 in females $5 \frac{1}{2}$ to 73 months after transplantation (mean 24 months). Ten of these cases followed transplants from a living donor. All patients received immunosuppressive treatment with azathioprine and prednisone, while 11 patients received additional immunosuppressive measures in the form of splenectomy (eight cases), antilymphocytic serum (five cases), or thymectomy (one case). All but three of the 18 patients are dead. In view of the fact that reticulum cell sarcoma usually spares the brain, ${ }^{5}$ it is of great interest that in nine of these cases that organ was involved, in six cases exclusively, while the two unclassified lymphomas were both confined to the brain.

Though the frequency of these lymphomas is undoubtedly increased in recipients of transplants, the extent of the increase is not yet known precisely. Some crude estimates have been made, and at a time when 14 lymphomas ( 12 reticulum cell sarcomas) had been recorded among approximately 4,000 recipients of transplants the incidence was estimated to be increased 50-fold over that for reticuloses other than Hodgkin's disease in the age group 20-49.6 Published incidence rates for reticulum cell sarcomas in the general population are often combined with those for lymphosar- coma, ${ }^{8}$ but if these two types of lymphoma are assumed to have similar frequencies in that age group the increased incidence of reticulum cell sarcomas among recipients of renal transplants is at least 100 -fold. But in absolute terms the risk is too small to weigh significantly against the performance of renal transplantation when the standard indications for it exist.

The increased incidence of lymphoid tumours among recipients of renal transplants does not in itself constitute support for the concept of an immunity mechanism acting against neoplasms in general, for that theory would imply that all types of cancers should increase in frequency. The incidence of non-lymphoid tumours in these patients is therefore of great interest. So far 2 leiomyosarcomas, 2 Kaposi's sarcomas, and at least 28 other tumours have been reported, ${ }^{3-5}$ including tumours of the testis ( 1 embryonal cell tumour), uterine cervix (5 cases in situ), lip (5), skin (4), lung (2), ovary (1 dysgerminoma), sigmoid colon (1), liver (1), and carcinomatosis with an unknown primary site. ${ }^{1}$ A gastric carcinoma has also been recorded in a heart transplant recipient. ${ }^{4}$ These tumours developed 2 to 75 months after transplantation. Almost certainly not included in this total of 28 are 7 patients recently reported from Australia who developed after renal transplantation a total of 16 squamous cell carcinomas, 1 basal-cell carcinoma, and 3 keratoacanthomas.

There seems little doubt that immunosuppression may sometimes facilitate the growth of malignant tissue, as illustrated by two remarkable cases of inadvertent transplantation of cancer in the grafted kidney. One such tumour secondary to a primary in the donor's bronchus presented in the recipient as an abdominal mass. ${ }^{9}$ Only a limited surgical removal was possible, but cessation of immunosuppression was followed by complete disappearance of malignant tissue at a later laparotomy. In another case, ${ }^{10}$ in which the primary was in the donor's liver, pulmonary metastases developed in the recipient but resolved after withdrawal of immunosuppressive treatment.

It is difficult to assess the significance of these nonlymphoid tumours. The detection of carcinoma in-situ of the uterine cervix may partly be due to the close clinical surveillance of transplant patients, while the large number of skin cancers may partly be due to the large numbers of transplants reported from places where there is a high level of exposure to the sun. With the possible exception of skin 
tumours there is no firm evidence of an increased incidence of any particular non-lymphoid tumour. Patients who have received transplants will, however, have to be followed up for much longer before a definite answer can be given, and a large-scale study on these lines, supported by the Cancer Research Campaign and the Medical Research Council, is in progress, organized from Oxford. 6

Possibilities other than a breakdown of immunological surveillance have been raised to explain this increased incidence of lymphomas. They include the proliferation of oncogenic viruses and the direct induction of neoplastic change by immunosuppressive drugs. The similarities between these post-transplant lymphomas and those which develop experimentally after the administration of azathioprine to immunologically deficient mice ${ }^{11}$ have been commented on, though their significance is uncertain. Certainly the increased incidence of reticulum cell sarcoma in transplant patients cannot confidently be attributed to their immunosuppressive treatment, and the presence of the graft with its continuous antigenic stimulation may be crucial. Furthermore, it is known that some lymphoid tissue is transferred with the grafted kidney, ${ }^{12}$ raising the possibility of a graft-versus-host reaction.

The incidence of malignant tumours in patients who have not received transplants but been treated with immunosuppressive drugs is therefore relevant to this question. One case of lymphosarcoma has been reported ${ }^{13}$ in a 66-yearold man with proliferative glomerulonephritis a few months after completing a year's treatment with azathioprine and prednisone. A reticulum cell sarcoma reported ${ }^{14}$ in a 60 year-old man after immunosuppressive treatment for chronic cold haemagglutinin disease may have been the basic disorder underlying his haemolytic anaemia. A cerebral lymphoma has recently been reported in a patient with systemic lupus erythematosus treated with azathioprine. ${ }^{18}$ Three nonlymphoid tumours reported in similarly treated patients-a malignant melanoma in a woman with systemic lupus erythematosus, ${ }^{15}$ a pancreatic sarcoma, ${ }^{16}$ and an adenocarcinoma of the colon ${ }^{17}$ in a man with long-standing ulcerative colitis-do not indicate an increased risk of malignancy in such patients. But the inclusion of medical patients treated with immunosuppressive drugs in the previously mentioned Oxford study ${ }^{6}$ should supply more precise information on this question.

1 Thomas, L., in Cellular and Humoral Aspects of the Hypersensitive States, ed. H. P. Lawrence, p. 529. London, Cassell, 1959.

Burnet, F. M. British Medical fournal, 1965, 1, 338.

3 Penn, Recent Results in Cancer Research, No. 35. Berlin, Springer-Verlag, 1970.

4 Penn, I., Halgrimson, C. G., and Starzl, T. E., Transplantation Proceedings, 1971, 3, 773 .

5 Schneck, S. A., and Penn, I., Lancet, 1971, 1, 983.

6 Doll, R., and Kinlen, L., British Medical fournal, 1970, 4, 420

7 Walder, B. K., Robertson, M. R., and Jeremy, D., Lancet, 1971, 2, 1282 .

8 Cancer Incidence in Five Continents, vol. 2, ed. R. Doll, C. Muir, and J. Waterhouse. Berlin, Springer-Verlag, 1970.

9 Wilson, R. E., et al., New England fournal of Medicine, 1968, 278, 479 .

10 Zukoski, C. F., et al., Transplantation, 1970, 9, 71.

11 Casey, T. P., Clinical and Experimental Immunology, 1968, 3, 305.

12 Wilson, W. E., and Kirkpatrick, C. H. in Experience in Renal Transplantation, ed. T. E. Starze. Philadelphia, W. B. Saunders, 1964. plantation, ed. T. E. Starze. Philadelphia, W. B. Saunders, 1964. Tournal, 1969, 2, 535 .

14 Worlledge, S. M., Brain, M. C., Cooper, A. C., Hobbs, J. R., and Dacie, J. V., Proceedings of the Royal Society of Medicine, 1968, 61, 1312 .

15 Manny, N., Rosenman, E., and Benbassat, J., British Medical fournal, 1972, 2, 291 .

16 Fusco, F. A., Mattioli, F., and Bertocchi, I., First Meeting of European Division of International Society of Haematology, 1971, abstract No. 343.

17 Patterson, Norton, R. A., and Schwartz, R. S., American fournal of Digestive, Diseases, 1971, 16, 327.

18 Lipsmeyer, E. A., Arthritis and Rheumatism, 1972, 15, 183.

\section{Maternal Deaths}

Every third year, when a new Report on Confidential Enquiries into Maternal Deaths in England and Wales appears, is a major event in the obstetric calender. The report for 1967-9, which has been recently published, ${ }^{1}$ is another signal for a review of past and present obstetrics practice, with a view to improving the prognosis of childbirth for the individual mother. The justification for these reports is that they should lead to modifications of clinical practice, since a survey on a national scale can highlight problems of which an individual doctor would be unaware in a lifetime. That they can and do modify practice is certain, and undoubtedly they have contributed to the great improvement in maternal mortality since the new form of reports began in 1952 .

In the period 1967-9 there were about 2,300,000 births, and the review covers 451 deaths-that is, $86.3 \%$ of maternal deaths recorded by the Registrar General. Though this a reasonable proportion, it could be better and doctors have little excuse for not co-operating in this valuable venture. Indeed, they could initiate inquiry into any maternal death coming to their notice by speaking to their local medical officer of health.

The major causes of death remained the same as in the last report of 1964-6-namely, abortion (115 cases), pulmonary embolism (75 cases), haemorrhage (41 cases), and toxaemia ( 51 cases). (Incidentally, it would be more in accord with modern clinical terminology to call this last condition pre-eclampsia). All other causes of death accounted for 173 cases. In 1952 the maternal mortality rate was 67 per 100,000 . By 1969 it was 19 per 100,000.

Both absolute numbers of deaths from abortion and the death rate have fallen steadily over the last six reports. In this last report the deaths numbered 117-of which 74 followed illegal abortion, 25 spontaneous abortion, and 18 legal abortion. The operation of the Abortion Act, which became effective in April 1968, has brought about a decrease in the deaths in the first category but an increase in those in the last group. The risk of coloured women dying of an illegal abortion seems to be especially high: of the 18 legal abortion deaths three followed the injection of utus past into the uterus. Perhaps this method should be abandoned despite some published good results. The figures also suggest the greater danger of termination in the second trimester and of sterilization combined with abortion.

Pulmonary embolism is still an enigma, snatching away some without any warning. But despite our ignorance of its aetiology the death rate is improving. The evidence suggests the special dangers of obesity, prolonged rest in bed in pregnancy (often because of pre-eclampsia or hypertension) and caesarean section. The report confirms the view that women of blood group $\mathbf{O}$ are less likely to develop embolism than those of the other groups, though the possible relation between oestrogens used to suppress lactation and thromboembolic deaths can neither be confirmed nor denied on the evidence presented in it. The diagnosis of thrombosis and of warning pulmonary emboli is still obviously difficult, and obviously there is a need for a very high index of suspicion. Moreover, policies for the use of anticoagulants are far from clear, and all units might profitably review them.

Deaths from haemorrhage should now be avoidable in most instances. Some patients with abruptio placentae still receive inadequate transfusion, and the lesson has not yet been learned of the danger of transporting a woman to hospital 